\title{
Pengaruh store atmosphere terhadap keputusan pembelian konsumen di Coffee Shop Lucky Coffee Kota Jambi
}

\author{
Renol Elmi Krisito*; Syahmardi Yacob; Yenny Yuniarti
}

\author{
Program Studi Manajemen Fakultas Ekonomi dan Bisnis Universitas Jambi \\ *E-mail korespodensi: renokrisito@gmail.com
}

\begin{abstract}
This study aimed to determine the effect of store atmosphere dimensions on purchasing decisions at Lucky Coffee Jambi City coffee shop. Data collection was carried out by distributing questionnaires. Based on the study results, it is suggested that Lucky Coffee keep the outside variable (X1) and purchase points (X4) to increase consumer purchasing decisions on Lucky Coffee. Data were analyzed with multiple linear regression analysis using statistical software SPSS 21. The results showed that the coefficient of determination showed an $R$ square of 0.752, which means that the store atmosphere affects purchasing decisions by $75.2 \%$. The remaining $24.8 \%$ is influenced by other factors not examined in this research. The F Store Atmosphere test involves purchasing decisions, evidenced by the F value of 71.834. In the T-test, it is known that the exterior (X1) has an effect of 5.346, the general interior (X2) is 1.315, the store layout (X3) is 0.423 , and the point of purchase $(X 4)$ is 2.079. From the results of this study, it can be concluded that the Store Atmosphere on individual purchasing decisions affects the outer dimensions of the store and the purchase points. In contrast, the general interior dimensions and store layout do not significantly affect purchasing decisions.
\end{abstract}

Keywords: store atmosphere, purchase decisions

\begin{abstract}
Abstrak
Tujuan dari penelitian ini adalah untuk mengetahui pengaruh dimensi Store Atmosphere terhadap keputusan pembelian di coffee shop Lucky Coffee Kota Jambi. Pengumpulan data dilakukan melalui penyebaran kuisioner. Berdasarkan hasil penelitian maka disarankan agar pihak Lucky Coffee untuk tetap mempertahankan variabel bagian luar toko (X1) dan poin pembelian (X4) agar dapat meningkatkan keputusan pembelian konsumen terhadap Lucky Coffee. Data dianalisis dengan analisis regresi linier berganda menggunakan software statistik SPSS 21. Hasil penelitian menunjukkan bahwa koefisien determinasi menunjukkan $\mathrm{R}$ square sebesar 0,752 yang artinya Store Atmosphere mempengaruhi keputusan pembelian sebesar $75,2 \%$ dan sisanya sebesar $24,8 \%$ dipengaruhi oleh faktor lain yang tidak diteliti dalam penelitian ini. Pada uji F Store Atmosphere berpengaruh terhadap keputusan pembelian dibuktikan dengan nilai $\mathrm{F}$ sebesar 71,834. Pada uji T diketahui bahwa Eksterior (X1) berpengaruh sebesar 5,346, Interior Umum (X2) sebesar 1,315, Tata Letak Toko (X3) sebesar 0,423, dan Titik Pembelian (X4) sebesar 2,079. Dari hasil penelitian ini dapat disimpulkan bahwa Store Atmosphere terhadap keputusan pembelian secara individu berpengaruh pada dimensi bagian luar toko dan poin pembelian, sedangkan pada dimensi interior umum dan tata letak toko justru tidak berpengaruh signifikan terhadap keputusan pembelian.
\end{abstract}

Kata kunci : store atmosphere, keputusan pembelian

PENDAHULUAN

Perkembangan jaman masyarakat kota pada saat ini telah mengalami perubahan gaya hidup (lifestyle). Gaya hidup urban yang digandrungi saat ini adalah kebiasaan 
kelompok masyarakat tertentu yang gemar berkumpul di cafe atau coffee shop, hal ini didukung oleh pendapat Rhenald Kasali (2010), seorang pakar di bidang pemasaran yang mengatakan bahwa saat ini ngopi kini bukan lagi sekedar untuk menghilangkan rasa kantuk, tapi sebagai bagian dari gaya hidup, dimana coffee shop menjadi tempat berkumpul yang amat diminati.

Salah satu coffee shop yang ada di Kota Jambi adalah Lucky Coffee yang berlokasi di kawasan Arizona, Kota Jambi. Selain Lucky coffee ada beberapa cafe yang menjadi pesaing, antara lain Goresan Cafe, dan Teanol. Lucky coffee memiliki store atmosphere yaitu desain dalam toko yang terdapat beberapa tempat duduk lesehan, kemudian terdapat hiasan dinding berupa daun-daun hiasan dan kata-kata motivasi, dan musik yang dihadirkan dapat memberikan peningkatan kenyamanan dalam menikmati produk dan menyenangkan hati pengunjung. Berikut data penjualan Lucky Coffee :

Tabel 1. Data penjualan lucky coffee

\begin{tabular}{ccc}
\hline No. & Bulan & Penjualan (cup) \\
\hline 1. & Oktober & 389 \\
2. & November & 496 \\
3. & Desember & 345 \\
4. & Januari & 291 \\
\hline
\end{tabular}

Sumber: Lucky Coffee, 2020

Store Atmosphere bisa menjadi alasan lebih bagi konsumen untuk tertarik dan membeli. Hal ini seperti yang dikemukakan oleh Levy dan Weitz (2001) dalam Lily Harlina Putri, dkk (2014) yang mengemukakan bahwa "Customer purchasing behavior is also influenced by the store atmosphere". Ketika konsumen memutuskan untuk membeli suatu produk sebenarnya mereka memiliki alasan-alasan tertentu dalam memilih sebuah produk, misalnya merasa puas dengan kualitas dan pelayanan yang ditawarkan produk tersebut

\section{TINJAUAN PUSTAKA}

\section{Store atmosphere}

Menurut Utami (2007) bahwa atmosphere merupakan kombinasi dari karakteristik fisik seperti arsiterktur, tata letak (display), pencahayaan, warna, temperatur, music, serta aroma yang bertujuan untuk merancang respons emosional dan persepsi pelanggan dan untuk mempengaruhi pelanggan dalam membeli barang.

Dari pernyataan diatas dapat diketahui bahwa tujuan dari atmosphere dan penataan suatu suasana lingkungan toko adalah untuk mempengaruhi perhatian dan keinginan konsumen untuk mengunjungi toko tersebut, sehingga dapat mempengaruhi keputusan pembelian konsumen. Dimana konsumen yang berkunjung merasa mudah untuk mencari barangang dibutuhkan, mempertahankan mereka untuk berlama- lama berada di dalam, memotivasi untuk membuat perencanaan secara mendadak, mempengaruhi mereka untuk melakukan pembelian, dan memberikan kepuasan dalam berbelanja. Dengan demikian dapat disimpulkan bahwa atmosphere yang dilaksanakan dengan baik akan memberikan pengaruh positif terhadap keputusan pembelian konsumen.

Dalam penelitian lain menurut Berman \& Evans (2010) dapat dibagi menjadi empat elemen utama, yaitu: bagian luar toko (exterior), general interior (interior umum), store layout (tata letak toko), interior (point of purchase)

\section{Keputusan pembelian}

Menurut Amirullah (2002) mendefinisikan keputusan konsumen adalah suatu proses dimana konsumen melakukan penilaian terhadap berbagai alternatif pilihan, dan memilih salah satu atau lebih alternatif yang diperlukan berdasarkan pertimbangan- 
pertimbangan tertentu. Menurut Assael dalam Sutisna (2002) Penjelasan proses pengambilan keputusan ada lima tahap yaitu:

Pengenalan masalah (problem recognition).Pada tahap ini konsumen mempunyai kesadaran atas pemenuhan kebutuhan dan keinginan (need arousal). Pengenalan masalah terjadi bila suatu kebutuhan dirasakan oleh keadaan konsumen. Keadaan konsumen dipengaruhi oleh stimulasi, persepsi, aspirasi dan lingkungan (seperti kebudayaan, kelompok acuan, dan gaya hidup).

Penelusuran informasi (information search).Pada tahap ini konsumen akan mencari informasi mengenai keberadaan produk yang diinginkannya. Proses pencarian informasi ini akan dilakukan dengan mengumpulkan semua informasi yang berhubungan dengan produk yang diinginkan.

Evaluasi alternatif (alternative evaluation). Pada tahap evaluasi alternatif dari proses pemilihan atau akuisisi, kosumen membandingkan pilihan yang diindentifikasikan sebagai cara yang potensial mampu memecahkan masalah yang mengawali proses keputusan.

Pilihan (choice)Setelah mengevaluasi semua alternatif, langkah konsumen berikutnya dalam proses pengambilan keputusan adalah membuat pilihan. Para konsumen memilih merek atau jasaalternatif, menentukan pilihan diantara toko- toko.

Hasil(Outcomes). Proses evaluasi ini akan menentukan apakah konsumen merasa puas atau tidak atas keputusan pembeliannya. Seandainya konsumen merasa puas, maka untuk melakukan pembelian kembali pada masa depan akan terjadi, sementara itu jika konsumen tidak puas atas keputusan pembeliannya, konsumen akan mencari kembali berbagai informasi produk yang dibutuhkannya.

\section{METODE}

\section{Populasi dan sampel}

Populasi pada penelitian ini berjumlah sekitar 1521 pembeli. Dengan asumsi 1 cup minuman kopi atau non-kopi dibeli oleh 1 orang. Berdasarkan penelitian ini, sasaran populasi penulis adalah kedai kopi Lucky Coffe di Mayang Mangurai, Kota Jambi. Pengambilan sampel sebanyak 100 responden yang merupakan konsumen Lucky Coffee.

\section{Sumber data}

Data primer dikumpulkan dengan menggunkan kuesioner yang disebar secara langsung, sedangkan data sekunder diperleh dari berbagi sumber termasuk coffe shop Lucky Coffee dan beragai literatur-literatur beserta jurnal yang berkaitan dengan penelitian.

\section{Analisi dan alat analisis data}

Dari hasil kuesioner, data menggunakan distribusi frekuensi untuk memperleh nilai rata-rata. Selnajutnya data dianalisi menggunakan pendekatan analisis regresi berganda.

\section{Variabel penelitian}

Variabel bagian luar toko (X1), interior umum (X2), tata letak toko (X3), dan poin pembelian (X4) yang merupakan variabel independen dan keputusan pembelian (Y) merupakan variabel dependen.

\section{HASIL DAN PEMBAHASAN}

\section{Karakteristik responden berdasarkan usia}

Berdasarkan penelitian yang dilakukan, dapat dikelompokkan karakteristik responden yang paling banyak sebagai berikut : 
Tabel 2 Karakteristik responden berdasarkan usia

\begin{tabular}{|c|c|c|c|}
\hline No. & Uraian & Jumlah & $\%$ \\
\hline 1. & Usia 18-25th & 86 & $86 \%$ \\
\hline 2. & Jenis Kelamin Laki-Laki & 59 & $59 \%$ \\
\hline 3. & Tingkat Pendidikan SMA & 48 & $48 \%$ \\
\hline 4. & Pekerjaan Lainnya & 59 & $59 \%$ \\
\hline 5. & Jumlah penghasilan $>2.000 .000$ & 34 & $34 \%$ \\
\hline 6. & Waktu Berkunjung Jam 1-3 & 26 & $26 \%$ \\
\hline 7. & Berbelanja ulang 3-5 kali & 41 & $41 \%$ \\
\hline
\end{tabular}

\section{Uji statistik}

Hasil uji validitas dari seluruh variabel penelitian menunjukan kondisi valid, dengan r tabel $(0,1654)$. Sama dengan itu, uji reliabilitas menggunakan cronbach alpha lebih besar dari 0,7 yaitu sebesar 0,941 untuk bagian luar toko, 0,944 untuk interior umum,0,925 untuk tata letak toko, dan 0,864 untuk poin pembelian dan 0,940 untuk keputusan pembelian. Dengan demikian maka dapat dilanjutkan uji statistik untuk kepentingan pengujian hipotesis.

Tabel 3 ringkasan hasil uji statistik analisis regresi linear berganda :

\section{Coefficients ${ }^{a}$}

\begin{tabular}{|c|c|c|c|c|c|c|}
\hline \multirow{2}{*}{ Model } & \multicolumn{2}{|c|}{$\begin{array}{l}\text { Unstandardized } \\
\text { Coefficients }\end{array}$} & $\begin{array}{c}\text { Stand } \\
\text { ardize } \\
\text { d } \\
\end{array}$ & \multirow{2}{*}{$\mathbf{T}$} & \multicolumn{2}{|c|}{$\begin{array}{l}\text { Collinearity } \\
\text { Statistics }\end{array}$} \\
\hline & B & $\begin{array}{l}\text { Std. } \\
\text { Error }\end{array}$ & Beta & & Tolerance & VIF \\
\hline $\begin{array}{l}\text { (Constant) } \\
\text { BagianLuarToko }\end{array}$ & 2,458 & 1,327 & & $1,852,067$ & & \\
\hline $\begin{array}{l}\text { InteriorUmum } \\
\text { TataLetakToko }\end{array}$ &, 552 & ,103 &, 547 & $5,346,000$ & ,250 & 3,999 \\
\hline \multirow[t]{3}{*}{ PoinPembelian } &, 122 & ,093 &, 143 & $1,315,192$ &, 220 & 4,553 \\
\hline & ,080 & ,189 &, 044 & 674, 423, & ,241 & 4,149 \\
\hline & ,506 &, 243 & , 193 & $2,079,040$ & ,304 & 3,289 \\
\hline
\end{tabular}

Dependent Variable: KeputusanPembelian

Sumber: Data diolah, 2020

Berdasarkan keterangan pada Tabel maka diperoleh persamaan regresi sebagai berikut:

$\mathrm{Y}=\alpha+\beta \mathrm{X} 1+\beta \mathrm{X} 2+\beta \mathrm{X} 3+\beta \mathrm{X} 4+\mathrm{e}$

$\mathrm{Y}=2,458+0,552 \mathrm{X} 1+0,122 \mathrm{X} 2+0,080 \mathrm{X} 3+0,506 \mathrm{X} 4+\mathrm{e}$

Persamaan regresi linear tersebut dapat diinterpretasikan sebagai berikut:

Konstanta sebesar 2,458 memberikan arti bahwa apabila Store Atmosphere $(\mathrm{X})$, diasumsikan $=0$, maka Keputusan Pembelian $(\mathrm{Y})$ secara konstan bernilai 2,458. Koefisien regresi varibel Bagian Luar Toko (X1) sebesar 0,552 memberikan arti bagian luar toko berpengaruh positif terhadap keputusan pembelian, Interior Umum (X2) sebesar 0,122 memberikan arti interior umum berpengaruh positif terhadap keputusan pembelian, Tata Letak Toko (X3) sebesar 0,080 memberikan arti tata letak toko 
berpengaruh positif terhadap keputusan pembelian dan Poin Pembelian (X4) sebesar 0,506 memberikan arti bahwa poin pembelian berpengaruh positif terhadap Keputusan Pembelian. Berikut adalah tabel ringkasan hasil uji f dan tabel koefisien determinasi $\left(\mathrm{R}^{2}\right)$.

\section{Hasil uji statistik t}

Tabel 4. Pengaruh store atmosphere terhadap keputusan pembelian konsumen ANOVA

\begin{tabular}{llcllll}
\hline \multicolumn{1}{c}{ Model } & \multicolumn{1}{c}{$\begin{array}{c}\text { Sum of } \\
\text { Squares }\end{array}$} & Df & $\begin{array}{c}\text { Mean } \\
\text { Square }\end{array}$ & F & Sig. \\
\hline Regression & 2391,804 & 4 & 597,951 & 71,834 &, $000^{\mathrm{b}}$ \\
& 790,786 & 95 & 8,324 & & \\
Residual & 3182,590 & 99 & & &
\end{tabular}

Dependent variable: keputusanpembelian, predictors: (constant), poin pembelian, bagian luar toko, tata letaktoko, interior umum

Tabel 5. Koefisien determinasi store atmosphere terhadap keputusan pembelian konsumen

Model Summaryb

\begin{tabular}{|c|c|c|c|}
\hline & & R Square & $\begin{array}{c}\text { Adjusted R } \\
\text { Souare }\end{array}$ \\
\hline
\end{tabular}

$1 \quad, 867^{\mathrm{a}} \quad, 752 \quad, 7412,885$

Predictors: (constant), poin pembelian, bagian luar toko, tata letak toko, interior umum, dependent variable: keputusan pembelian

\section{KESIMPULAN DAN SARAN}

\section{Kesimpulan}

Berdasarkan hasil penelitian dan pembahasan mengenai Pengaruh Store Atmosphere terhadap keputusan pembelian di Lucky Coffee Kota Jambi maka dapat ditarik kesimpulan sebagai berikut:

Store Atmosphere terhadap keputusan pembelian secara individu berpengaruh pada dimensi bagian luar toko dan poin pembelian, sedangkan pada dimensi interior umum dan tata letak toko justru tidak berpengaruh signifikan terhadap keputusan pembelian. Store Atmosphere terhadap keputusan pembelian secara bersamaan ternyata berpengaruh signifikan dan menunjukkan arah positif.

\section{Saran}

Berdasarkan hasil penelitian dan pembahasan diatas, ada beberapa hal yang peneliti ingin berikan yaitu masukan atau berupa saran-saran kepada pihak yang bersangkutan yaitu sebagai berikut:

Bagi para peneliti lain hendaknya memperluas subjek penelitian yang digunakan, misalnya Cafe lainnya yang ada di Kota jambi. Bagi peneliti selanjutnya hendaknya melakukan penelitian dan pengamatan dalam jangka waktu yang cukup, guna mendapatkan semua data yang diperlukan dalam proses penelitian. Bagi penelitian selanjutnya dapat mengembangkan variabel-variabel lain yang mempengaruhi keputusan pembelian seperti Brand Image, Harga , dan variabel-variabel lainnya yang berpengaruh terhadap keputusan pembelian. 
Diharapkan memberikan inovasi yang berkelanjutan dan stimulus lainnya untuk memberikan pengalaman konsumsi kepada konsumen mengenai konsep pelayanan yang unik dan kuat, sehingga dapat menunjang harapan konsumen. Hal ini diharapkan dapat terus meningkatkan daya tarik Lucky Coffee itu sendiri. Berdasarkan hasil penelitian ini, konsumen Lucky Coffe lebih memperhatikan Bagian Luar Toko dan Poin Pembelian dan diharapkan kepada Lucky Coffee untuk lebih meningkatkan aspek interior umum dan tata letak toko agar bisa menunjang keputusan pembelian konsumen.

\section{DAFTAR PUSTAKA}

Dickinson, JR (2019, Maret). Kesulitan memvariasikan lintas topik (yaitu, bab) dalam teks pemasaran terpilih. dalam perkembangan simulasi bisnis dan pembelajaran eksperiensial: Prosiding konferensi ABSEL Tahunan (Vol. 46).

Girsang, P. J. (2013). Pengaruh store atmosphere dan product assortment terhadap minat beli pada the secret factory outlet Bandung. IMAGE: Jurnal Riset Manajemen, 3(1).

Hutama, C. L. (2014). Analisa pengaruh dining experience terhadap behavioral intention dengan customer satisfaction sebagai variabel intervening (studi kasus: domicile kitchen and lounge). Jurnal Strategi Pemasaran, 2(1), 1-8

Mowen, J. C., \& Minor, M. (2002). Perilaku konsumen. Jakarta: Erlangga, 90.

Octaviani, N. C., Kuleh, Y., \& Wahyuni, S. (2021). Pengaruh store atmosphere dan harga terhadap keputusan pembelian (studi kasus konsumen Warunk Upnormal Samarinda). Jurnal Ilmu Manajemen Mulawarman (JIMM), 5(2).

Purnomo, AK (2017). Pengaruh suasana kafe terhadap keputusan pembelian gen y pada Old Bens Cafe. Jurnal Manajemen Maranatha , 16 (2), 133-144.

Putri, L. H. (2014). Pengaruh store atmosphere terhadap keputusan pembelian dan kepuasan pelanggan (Studi pada monopoli Cafe and Resto Soekarno Hatta Malang). Jurnal Administrasi Bisnis, 15(2).

Putri, L. H. (2014). Pengaruh store atmosphere terhadap keputusan pembelian dan kepuasan pelanggan (Studi pada monopoli Cafe and Resto Soekarno Hatta Malang). Jurnal Administrasi Bisnis, 15(2).

Rorimpandey, J. N., Sepang, J. L., \& Arie, F. V. (2017). Analisis pengaruh store atmosphere dan keanekaragaman produk terhadap loyalitas konsumen di Café Black Cup Coffee \& Roastery. Jurnal EMBA: Jurnal Riset Ekonomi, Manajemen, Bisnis dan Akuntansi, 5(2).

Sentoso, AC, \& Poniman, AS (2015). Analisa faktor yang menjadi preferensi konsumen dalam memilih kedai kopi di Surabaya. Jurnal Hospitality dan Manajemen Jasa , 3 (1), 1-11.

Sumarwan, U. (2011). Perilaku konsumen: teori dan penerapannya dalam pemasaran. Bogor: Ghalia Indonesia. Jakarta: Ghalia Indonesia

Turley, LW, \& Milliman, RE (2000). Efek atmosfer pada perilaku belanja: review dari bukti eksperimental. Jurnal penelitian bisnis , 49 (2), 193-211.

Valentine, K., \& Widodo, A. (2014). Pengaruh store atmosphere terhadap keputusan pembelian pada dakken coffee \& steak Bandung. eProsiding Manajemen , 1 (3).

Whidya Utami, C. (2006). Manajemen ritel. Jakarta, Salemba Empat. 